\title{
Correlation between Asthma Severity and Serum Vitamin D Levels: Experience from a Tertiary Care Centre in North India
}

\author{
Haider Guru ${ }^{1}$, Sonaullah Shah ${ }^{1}$, Roohi Rasool2*, Qurteeba Qadri², Taha ashraf ${ }^{3}$ and Syed Mehvish \\ Yawar 4 \\ ${ }^{1}$ Department of Internal Medicine, SKIMS, Srinagar, Jammu and Kashmir, India \\ ${ }^{2}$ Department of Immunology \& Molecular Medicine, SKIMS, Srinagar, Jammu and Kashmir, India \\ ${ }^{3}$ Department of Clinical Biochemistry, SKIMS, Srinagar, Jammu and Kashmir, India \\ ${ }^{4} \mathrm{GMC}$, Srinagar, India
}

${ }^{*}$ Corresponding author: Roohi Rasool, Sher-i-Kashmir Institute of Medical Sciences (SKIMS), Srinagar, Jammu and Kashmir, India, Tel: +919419077662; E-mail: roohi_wani@yahoo.com

Received date: Aug 09, 2018; Accepted date: Aug 30, 2018; Published date: Sep 2, 2018

Copyright: (C) 2018 Guru H, et al. This is an open-access article distributed under the terms of the Creative Commons Attribution License, which permits unrestricted use, distribution, and reproduction in any medium, provided the original author and source are credited.

Citation: Guru H, Shah S, Rasool R, Qadri Q, Guru FR, et al. (2018) Correlation between Asthma Severity and Serum Vitamin D Levels: Experience from a Tertiary Care Centre in North India. J Biomedical Sci Vol.7 No.3: 12.

\section{Abstract}

Asthma is a chronic immunological disorder of the lungs characterized by reversible airway obstruction, airway inflammation, and increased airway hyper responsiveness in response to provocative challenges.

Objective: The aim of this study is to assess the level of serum vitamin $D$ in patients with bronchial asthma and its correlation with disease severity.

Methods: The present study, included 120 patients diagnosed as bronchial asthma. The patients were grouped on the basis of vitamin D sufficiency and vitamin D levels were correlated with disease severity and lung function.

Results: Vitamin D deficiency was highly prevalent in asthmatic patients, and there was a direct and a significant relationship between serum vitamin $D$ levels, severity of asthma, control of asthma, serum IgE levels, sputum eosinophils and lung function.

Conclusions: Measuring serum levels of vitamin D followed by supplementation could be considered in the routine assessment of patients with bronchial asthma.

\section{Keywords Bronchial asthma; Disease severity; Vitamin D;} Atopy

\section{Introduction}

Asthma is a chronic immunological disorder of the lungs characterized by reversible airway obstruction, airway inflammation, and increased airway hyper responsiveness in response to provocative challenges [1]. It is a prevalent disease worldwide that has significant social and financial burden on the individuals affected [2,3]. Management of asthma includes multiple modalities and a step-up approach in its pharmacotherapy has been suggested. Increasing evidence demonstrates that vitamin $\mathrm{D}$ deficiency plays a role in chronic diseases including asthma [4]. Vitamin D is a fat-soluble nutrient and a secosteroid hormone which is widely recognized as a modulator of calcium absorption and bone health and also plays a role in regulating neuromuscular function, cellular differentiation, insulin secretion and blood pressure [5]. Vitamin $D$ insufficiency is increasingly recognized in the general population, and has been largely attributed to dietary, lifestyle and behavioral changes [6,7]. While its musculoskeletal consequences are well established, a new hypothesis links asthma to subnormal vitamin D levels [8-10].

Vitamin $D$ has several effects on the innate and adaptive immune systems that might be relevant in the primary prevention of asthma, in the protection against or reduction of asthma morbidity, and in the modulation of the severity of asthma exacerbations $[11,12]$. Vitamin $D$ has been shown to have a role in both innate and adaptive immunity by promoting phagocytosis and modulating the effects of Th1, Th2 and regulatory $T$ cells $[13,14]$. Vitamin $D$ deficiency has been associated with increased airway hyperresponsiveness (AWH), lower pulmonary function, worse asthma control and steroid resistance [15].

Cross-sectional data indicate that low 25(OH)D levels in patients with mild to moderate asthma are correlated with poor asthma control, reduced lung function, reduced glucocorticoid response, more frequent exacerbations, and consequent increased steroid use [16]. An analysis of the Third National Health and Nutrition Examination Survey (NHANES III) showed an association between serum vitamin $D$ levels and respiratory infections. Further, a correlation was seen in patients with asthma and COPD suggesting that the role of vitamin D may be more significant in these populations [17]. Another population- 
based study suggests a strong relationship between serum concentrations of 25-hydroxyvitamin D, forced expiratory volume in 1s (FEV1), and forced vital capacity, as lower pulmonary function is associated with vitamin D deficiency [18].

Therefore, the aim of this study was to prospectively investigate the relationship of vitamin $D$ levels with markers of asthma severity and control in asthmatic patients.

\section{Methods}

This was a prospective study conducted in the Dept of General Medicine in collaboration with Dept. of Immunology and Molecular Medicine Sher-i-Kashmir Institute of Medical Sciences over a period of two years (2014 to 2016). Patients were taken up for study from the General Medicine OPD, Pulmonary disease clinics and Allergy, Immunology clinic. One hundred twenty patients were diagnosed as asthmatics as per current Global Initiative for Asthma (GINA) criteria. Written informed consent was obtained from patients prior to inclusion in the study, ethical clearance was sort from institute ethical committee and the study was approved by the Institutional Research Board (IRB) of Sher-i-Kashmir Institute of Medical Sciences, Srinagar (IEC/SKIMS Protocol\#238/2014).

\section{Inclusion criteria}

1. Age above 18 years and below 80 years.

2. Both genders

3. Clinical findings and spirometry interpretations consistent with diagnosis of bronchial asthma .

\section{Exclusion criteria}

1. Hospitalization during past 4 weeks.

2. Patient with any other respiratory and systemic disorders

3. Patients who have received medications including systemic steroids, bisphosphonates, sulfasalazine, omega 3 fatty acids, immunosuppressants, thiazides, phenytoin, phenobarbitone, carbamezapine, theophylline.

4. History of intake of vitamin D or calcium in the past one month.

Clinical examination of the patients was done and all the patients presenting with classical symptoms of asthma were subjected to further immunological and biochemical investigations. These included:

1. Sputum eosinophil count: eosinophilic (eosinophil count $\geq$ $3 \%)$ or non- eosinophilic was done by Rawlins method. Briefly, sputum was collected in sputum containers with minimum amount of $2 \mathrm{ml}$, centrifuged and separated from saliva.This was followed by preparation of a phosphate buffered saline and $0.1 \%$ dithiotheitol solution was added. This solution was added to sputum in 1:1 ratio. A smear was made, air dried and stained with Leishman stain and then analysed.

2. Blood eosinophil count: was estimated by scatter impedence on a Beckman Coulter analyzer.

3. Serum IgE level measurement: was estimated by chemiluminescence on Beckman Coulter analyzer.

4. Serum 25-hydroxy vitamin D (25(OH)D) levels: was estimated by chemiluminescence on Beckman Coulter analyzer.

5. Spirometry: Pre and post bronchodilator spirometry was done to measure forced expiratory volume in first second (FEV1) in Liters, forced vital capacity (FVC) in Liters, FEV1/ FVC, reversibility i.e. increase in FEVI of $\geq 12 \%$ and $\geq 200 \mathrm{ml}$ from baseline, 10-15 minutes after 200 ug salbutamol inhalation. Patients were instructed not to take any bronchodilators for six hours and oral theophylline for at least twenty four hours prior to test. Maximal expiratory flow volume loops were obtained on a rolling seal spirometer. Reversibility was tested twenty minutes after the administration of $200 \mu \mathrm{g}$ of inhaled salbutamol. At least three acceptable and repeatable manoeuvres were obtained as recommended by the American Thoracic Society. FVC, FEV1, FEV1/FVC\% were measured using the selection criteria of ATS.

\section{Stastistical analysis}

All the data was subjected to statistical analysis using SPSS version 21 . The data was presented as mean \pm standard deviation (SD). The difference in the mean baseline values of various measurements within the group and between the groups was made using student's t-test. The data was analysed using person chi square test, odds ratio, $A$ two tailed $P$ value of $<0.05$ was considered significant.

\section{Results}

The asthma patients, who were having a sufficient level of Vitamin D were taken as controls in the study. The age of the subjects in the study group ranged from 18 to 80 years with a mean of $30.81 \pm 8.97$. The gender distribution of the study subjects revealed that there were 72 males (60\%) and 48 females (40\%). $57.5 \%$ of patients were smokers and $42.5 \%$ were nonsmokers. In our study, serum levels of vitamin D, pulmonary function tests, asthma control test score were analysed in 120 asthmatic patients who were divided into vitamin $D$ sufficient and vitamin $D$ insufficient group. The patients were further classified as intermittent, mild, moderate, severe asthmatics depending on the severity of asthma. Vitamin D deficiency was highly prevalent in asthmatic patients, and there was a direct and a significant relationship between serum vitamin $D$ levels, severity of asthma, control of asthma, serum IgE levels, sputum eosinophils and lung function (Tables 1-4).

Table 1 Relationship of Vitamin D levels on the status of sputum eosinophil count, absolute serum eosinophil count and serum IgE levels. 


\begin{tabular}{|c|c|c|c|c|c|}
\hline Parameters & Serum Vitamin D Status & Number of patients & Mean & Standard Deviation & P-value \\
\hline \multirow[b]{2}{*}{ Sputum eosinophil Count ( \%) } & Deficient & 65 & 9.838 & 4.4345 & \multirow[b]{2}{*}{$\leq 0.0001$} \\
\hline & Sufficient & 55 & 1.722 & 1.7311 & \\
\hline \multirow[b]{2}{*}{ Absolute Serum Eosinophil Count } & Deficient & 65 & 557.17 & 51.43 & \multirow[b]{2}{*}{$\leq 0.0001$} \\
\hline & Sufficient & 55 & 239.85 & 20.017 & \\
\hline \multirow[b]{2}{*}{ Serum lgE ( units/ml) } & Deficient & 65 & 783.584 & 77.1 & \multirow[b]{2}{*}{$\leq 0.0001$} \\
\hline & Sufficient & 55 & 235.381 & 35.79 & \\
\hline
\end{tabular}

Table 2 Relation of Atopy with Vitamin D Status.

\begin{tabular}{|l|l|l|l|}
\hline Atopy & Vitamin D deficient group 65 (n\%) & Vitamin D sufficient group 55 (n\%) & P value \\
\hline Present & $36(55 \%)$ & $17(30.90 \%)$ & \\
\cline { 1 - 3 } Absent & $29(44.6 \%)$ & $38(69 \%)$ & $>0.05$ \\
\hline
\end{tabular}

Table 3 Asthma severity and its association with vitamin D levels in asthmatics.

\begin{tabular}{|l|l|l|}
\hline Asthma Severity N (\%) & $\begin{array}{l}\text { Asthmatics with insufficient Vitamin } \mathbf{D} \\
\mathbf{( N = 6 5 )}\end{array}$ & $\begin{array}{l}\text { Asthmatics with sufficient Vitamin } \mathbf{D} \\
\mathbf{( N = 5 5 )}\end{array}$ \\
\hline Intermittent & $11(16.9 \%)$ & $15(27.27 \%)$ \\
\hline Mild & $13(20 \%)$ & $22(40 \%)$ \\
\hline Moderate & $11(16.9 \%)$ & $11(20 \%)$ \\
\hline Severe & $30(46.1 \%)$ & $7(12.7 \%)$ \\
\hline
\end{tabular}

Table 4 Association of Vitamin D status with lung function.

\begin{tabular}{|l|l|l|}
\hline $\begin{array}{l}\text { Asthma } \\
\text { Severity }\end{array}$ & $\begin{array}{l}\text { Vitamin D deficient group } \\
(\mathbf{N}=65)\end{array}$ & $\begin{array}{l}\text { Vitamin D sufficient group } \\
(\mathbf{N}=55)\end{array}$ \\
\hline $\begin{array}{l}\text { FEV1 (Mean) } \\
\%\end{array}$ & $65 \pm 4$ & $76 \pm 7$ \\
\hline
\end{tabular}

\section{Discussion}

Asthma is a common chronic inflammatory condition of the airways resulting in airway inflammation. The bronchi are hyperactive and narrow in response to a wide range of stimuli, initially reversible which may progress to irreversible obstruction to airflow [19]. Because vitamin D promotes steroid sensitivity in the body, can down regulate an inflammatory state via gene expression and cytokines production, its action could be directly on the airway. Deficiency of Vitamin D could be associated with an inability to switch off the inflammatory state, following an acute inhalational insult, with up regulation of prostaglandin, leukotrienes, macrophages, $\mathrm{T}$ cell activity and recruitment $[20,21]$. Vitamin D also inhibits the formation of matrix metalloproteinase as well as fibroblast proliferation and influences collagen synthesis; therefore suggesting the role of 1,25-dihydroxy vitamin $D$ in tissue remodeling and probably lung function [22]. Vitamin D influences airway remodeling by affecting smooth muscle cell movement, growth, and contractility and by inhibiting transforming growth factor-b and matrix metalloproteinase as well as fibroblast proliferation [23].
Serum IgE levels are associated with bronchial hyper responsiveness and asthma independently of atopy status and specific allergic sensitizations [24]. In the present study, serum IgE levels in the vitamin D sufficient group was significantly lower as compared to the deficient group ( $p<0.001)$. Satwani et al found serum total IgE to be a good predictor of allergy and significantly associated with severity of asthma [25]. Borish et al. also demonstrated that severe asthma patients had higher IgE levels compared to mild asthma [26]. Our findings are in accordance with these studies. The correlation between the serum IgE levels and asthma severity points towards the clinical application of anti IgE therapy for treatment and maintainance of moderate and severe asthma.

The present study also showed that asthmatics with insufficient vitamin $D$ had a higher mean for sputum eosinophils than with sufficient vitamin $D(P$ value $<0.0001)$ as well as higher absolute eosinophil counts as compared to the sufficient group $(p<0.05)$. These results have also been observed by Brehm and colleagues, who showed that higher vitamin $D$ levels were inversely associated with IgE, sputum eosinophil and peripheral blood eosinophil counts and was associated with reduced hospitalization rates, lower use of anti-inflammatory medications for asthma and less airway hyper responsiveness. In contrast, bronchial asthma patients with vitamin D insufficiency had significantly higher sputum eosinophil \% and a significantly lower FEV1\% than bronchial asthma patients with sufficient vitamin D [27]. 
The degree of severity of asthma was inversely associated with lower vitamin $D$ levels $(P<0.001)$. Our observations correspond with those reported by Shebl et al We also observed atopy was higher in asthmatic patients with vitamin D insufficiency than those without vitamin D insufficiency [28].

Although the above studies suggest an important role of Vitamin $D$ in prevention and management of asthma, some other studies have reported a rather contradicting role of Vitamin $D$ in inflammation. Studies on murine models suggest that vitamin D may induce a shift in the balance between Th1 and Th2-type cytokines toward Th2 dominance [29]. Further, Matheu et al [30] have shown that vitamin D has dual effects of both enhancing and suppressing allergic Th2 responses in a murine model of pulmonary eosinophilic inflammation.

\section{Conclusions}

We conclude that vitamin D deficiency was highly prevalent in asthmatic patients, and there was a direct and a significant relationship between vitamin $D$ levels and severity of asthma, therefore measuring serum levels of vitamin $D$ followed by supplementation could be considered in the routine assessment of patients with bronchial asthma.

\section{Acknowledgement}

This work was funded by Sher-i-Kashmir Institute of Medical Sciences, SKIMS, Sours, Srinagar.

\section{Competing and conflicting Interests}

The authors declare that they have no competing interests.

\section{References}

1. Zhao CN, Fan Y, Huang JJ, Zhang HX, Gao T, et al. (2015) The Association of GSDMB and ORMDL3 gene polymorphisms with asthma: a meta-analysis. Allergy Asthma Immunol Res 7: 175-185.

2. Mannino DM, Homa DM, Akinbami LJ, Moorman JE, Gwynn C, et al. (2002) Surveillance for asthma- United States, 1980-1999 MMWR Surveill Summ 51: 1-13.

3. Moorman JE, Rudd RA, Johnson CA, King M, Minor P, et al. (2007) National surveillance for asthma- United States, 1980-2004 MMWR Surveill Summ 56: 1-54.

4. Holick MF (2007) Vitamin D deficiency. N Engl J Med 357: 266-281.

5. LoPiccolo MC, Lim HW (2010) Vitamin D in health and disease. Photodermatol Photoimmunol Photomed 26: 224-229.

6. Holick MF (2007) Vitamin D deficiency. N Engl J Med 357: 266-281.

7. Paul G, Brehm JM, Alcorn JF, Holguin F, Aujla S, et al. (2012) Vitamin D and asthma, Am J Respir Crit Care Med 185: 124-132.

8. Camargo Jr CA, Rifas-Shiman SL, Litonjua AA, Rich-Edwards JW, Weiss ST, et al. (2007) Maternal intake of vitamin D during pregnancy and risk of recurrent wheeze in children at $3 \mathrm{y}$ of age, Am J Clin Nutr 85: 788-795.

9. Litonjua AA, Weiss ST (2007) Is vitamin D deficiency to blame for the asthma epidemic? J Allergy Clin Immunol 120: 1031-1035.
10. Ginde AA, Sutherland ER (2010) Vitamin D in asthma: Panacea or true promise? J Allergy Clin Immunol 126: 59-60.

11. Brehm JM, Schuemann B, Fuhlbrigge AL, Hollis BW, Strunk RC, et al. (2010) Serum vitamin D levels and severe asthma exacerbations in the Childhood Asthma Management Program study. J Allergy Clin Immunol 126: 52-58.

12. Goleva E, Searing DA, Jackson LP, Richers BN, Leung DY (2012) Steroid requirements and immune associations with vitamin $D$ are stronger in children than adults with asthma. J Allergy Clin Immunol 129: 1243-1251.

13. Gombart AF, Borregaard N, Koeffler HP (2005) Human cathelicidin antimicrobial peptide (CAMP) gene is a direct target of the vitamin $D$ receptor and is strongly up-regulated in myeloid cells by 1,25 dihydroxyvitamin D3. FASEB J 19: 1067-1077.

14. Matheu V, Bäck O, Mondoc E, Issazadeh-Navikas S (2003) Dual effects of vitamin D-induced alteration of TH1/TH2 cytokine expression: enhancing IgE production and decreasing airway eosinophilia in murine allergic airway disease. J Allergy Clin Immunol 112: 585-592.

15. Sandhu MS, Casale TB (2010) The role of vitamin D in asthma. Ann Allergy Asthma Immunol 105: 191-199.

16. Wu AC, Tantisira K, Li L, Fuhlbrigge AL, Weiss ST, et al. (2012) Childhood Asthma Management Program Research Group. Effect of vitamin $D$ and inhaled corticosteroid treatment on lung function in children. Am J Respir Crit Care Med 186: 508-513.

17. Ginde AA, Mansbach JM, Camargo CA Jr (2009) Association between serum 25- hydroxyvitamin $D$ level and upper respiratory tract infection in the third National Health and Nutrition Examination Survey. Arch Intern Med 169: 384-390

18. Black PN, Scragg R (2005) Relationship between serum 25hydroxyvitamin $D$ and pulmonary function in the third National Health and Nutrition Examination Survey. Chest 128: 3792-3798.

19. Wayse V, Yousafzai A, Mogale K, Filteau S (2004) Association of subclinical vitamin $D$ deficiency with severe acute lower respiratory infection in Indian children under 5 y. Eur J Clin Nutr 58: 563.

20. Karatekin G, Kaya A, Salihoğlu Ö, Balci H, Nuhoğlu A (2009) Association of subclinical vitamin $D$ deficiency in newborns with acute lower respiratory infection and their mothers. Eur J Clin Nutr 63: 473.

21. Ginde AA, Mansbach JM, Camargo CA (2009) Vitamin D, respiratory infections, and asthma. Curr Allergy Asthma Rep 9: 81-87.

22. Damera G, Fogle HW, Lim P, Goncharova EA, Zhao H, et al. (2009) Vitamin $D$ inhibits growth of human airway smooth muscle cells through growth factor-induced phosphorylation of retinoblastoma protein and checkpoint kinase 1. Br J Pharmacol 158: 1429-1441.

23. Gupta A, Sjoukes A, Richards D, Banya W, Hawrylowicz C, et al. (2011) Relationship between serum vitamin D, disease severity, and airway remodeling in children with asthma. Am J Respir Crit Care Med 184: 1342-1349.

24. Beeh KM, Ksoll M, Buhl R (2000) Elevation of total serum immunoglobulin $\mathrm{E}$ is associated with asthma in non allergic individuals. Eur Respir J 16: 609-614.

25. Satwani H, Rehman A, Ashraf S, Hassan A (2009) Is serum total IgE levels a good predictor of allergies in children? J Pak Med Assoc 59: 698-702. 
26. Borish L, Chipps B, Deniz Y, Gujrathi S, Zheng B, et al. (2005) Total serum IgE levels in a large cohort of patients with severe or difficult to treat asthma. Ann Allergy Asthma Immunol 95: 247-253.

27. Brehm JM, Schuemann B, Fuhlbrigge AL, Hollis BW, Strunk RC, et al. (2010) Childhood Asthma Management Program Research Group. Serum vitamin D levels and severe asthma exacerbations in the Childhood Asthma Management Program study. J Allergy Clin Immunol 126: 52-58.

28. Shebl R, Shehata SM, Elgabry M, Ali Al (2013) Vitamin D and phenotypes of bronchial asthma. Egypt J Chest Dis Tuberc 62: 201-205.
29. Cantorna MT, Zhu Y, Froicu M, Wittke A (2004) Vitamin D status, 1,25-dihydroxyvitamin D3, and the immune system. Am J Clin Nutr 80: 1717-1720.

30. Matheu V, Back O, Mondoc E, Issazadeh-Navikas S (2003) Dual effects of vitamin D-induced alteration of TH1/TH2 cytokine expression: enhancing IgE production and decreasing airway eosinophilia in murine allergic airway disease. J Allergy Clin Immunol 112: 585-592. 